\title{
ANTONIO TREJO Y LA CAPILLA DE LA INMACULADA CONCEPCIÓN DE LA CATEDRAL DE MURCIA (1623-1627). ARTE, DEVOCIÓN Y MEMORIA*
}

\author{
PABlo GonZÁlez TORNEL ${ }^{1}$ \\ Museo de Bellas Artes de Valencia / Universitat Jaume I
}

\begin{abstract}
Este artículo analiza el proceso constructivo y decorativo de la capilla de la Inmaculada Concepción de la Catedral de Murcia (1623-1627). A partir de la documentación de archivo, se desgranan los diferentes componentes de la reforma del trascoro catedralicio patrocinada por el obispo Antonio Trejo (1575-1635), arquitectura, escultura y reliquias, y se relacionan con su embajada en Roma por mandato de Felipe III. En último lugar, se interpreta el significado de la construcción como memorial del obispo Trejo.
\end{abstract}

Palabras clave: Murcia; Catedral; Inmaculada Concepción; Antonio Trejo; siglo XVII; Contrarreforma.

\section{ANTONIO TREJO AND THE CHAPEL OF THE IMMACULATE CONCEPTION IN MURCIA'S CATHEDRAL (1623-1627). ART, DEVOTION AND REMEMBRANCE}

This article analyzes the construction and decoration of the chapel of the Immaculate Conception in the Cathedral of Murcia (1623-1627). Using documentary evidences, it reassembles the different components of the reform of the Cathedral's retrochoir sponsored by Bishop Antonio Trejo (1575-1635), architecture, sculpture and relics, and connects the chapel with Trejo's diplomatic mission in Rome by mandate of Philip III. Finally, the building is interpreted as the memorial of Bishop Trejo.

Key words: Murcia; Cathedral; Immaculate Conception; Antonio Trejo; 17th century; Counter-Reformation.

Cómo citar este artículo / Citation: González Tornel, Pablo (2020) “Antonio Trejo y la capilla de la Inmaculada Concepción de la Catedral de Murcia (1623-1627). Arte, devoción y memoria”. En: Archivo Español de Arte, vol. 93, núm. 372, Madrid, pp. 321-334. https://doi.org/10.3989/aearte.2020.21

La figura de Antonio Trejo (1575-1635) es sobre todo conocida por su vinculación con la empresa hispana de la Inmaculada Concepción de la Virgen². En 1618 Felipe III designó al franciscano como embajador en Roma para la defensa del misterio y le nombró obispo de Cartagena ${ }^{3}$. Esta era la segunda de las misiones concepcionistas orquestadas por los Habsburgo españoles, y no sería la última. En 1616 Felipe III, ante la insistencia del arzobispo de Sevilla Pedro de Castro, había creado la Real Junta de la Inmaculada y había enviado a Roma a Plácido Tosantos para

\footnotetext{
* La investigación que ha dado lugar a este artículo ha sido financiada gracias al proyecto Inmaculada. Religiosidad y persuasión en la España del siglo XVII (UJI-B2019-02) del Plan de Promoción de la Investigación de la Universitat Jaume I 2019.

1 tornel@uji.es / ORCID iD: https://orcid.org/0000-0002-8599-0925

2 Su más reciente biografía en Sánchez-Rojas Fenoll, 2010: 549-568. Véanse también Nadal Iniesta, 2009, 1-14 y las reflexiones de Rivas Carmona, 2003, 153-176.

3 Pou y Martí, 1931: 76-166. Véase Pascual Martínez, 1974: 21-42.
} 
promover la definición dogmática de la doctrina ante Pablo V ${ }^{4}$. Décadas después, en 1659, Felipe IV enviaría a un nuevo emisario, Luis Crespí de Borja, que fue nombrado obispo de Plasencia para poder hacer frente a su misión ${ }^{5}$. Pese a que ninguna de estas embajadas consiguió el ansiado dogma, una serie de decretos papales fueron posicionando la doctrina oficial del Catolicismo de parte de la Inmaculada Concepción de María. En 1617, Pablo V Borghese firmó el decreto Sanctissimus Dominus noster prohibiendo cualquier expresión pública contra el concepcionis$\mathrm{mo}^{6}$. En 1622, un nuevo decreto de Gregorio XV Ludovisi, el Sanctissimus, prohibió contradecir la llamada pía opinión también en el ámbito privado7. Y en 1661, la constitución Sollicitudo omnium ecclesiarum, promulgada por Alejandro VII Chigi, designó la festividad del ocho de diciembre como dedicada a la Inmaculada Concepción ${ }^{8}$.

Antonio Trejo perteneció a la orden de San Francisco, aquella que más fervientemente había defendido el misterio de la Inmaculada Concepción ${ }^{9}$. Además, ya en 1611 Felipe III se había interesado por su promoción a general de los franciscanos ${ }^{10}$. Trejo conocía bien la corte romana y su funcionamiento, y desde allí había seguido manteniendo correspondencia con el rey sobre diferentes asuntos ${ }^{11}$. Por ello, cuando Felipe III decidió que el decreto de Pablo V en 1617 no había conseguido calmar los enfrentamientos entre concepcionistas y maculistas en España, Trejo entró a formar parte del engranaje de la política exterior de los Habsburgo ${ }^{12}$.

La ofensiva concepcionista española capitaneada por Antonio Trejo contó con una organización minuciosa, y entre los papeles del negociado de Roma se encuentran las cartas de adhesión a la causa de los cardenales Bonsi, Bellarmino, Lante, Campori, Toschi, Lancellotti, Montalto, Farnese, Mellini, Ginnasio, Crescenzi, Priuli, Varallo, de Siena, Aldobrandini y Giustiniani ${ }^{13}$. Junto a Trejo marchó como agente de Felipe III el también franciscano Luke Wadding, quien permaneció después en Roma realizando notables servicios a la causa de la Inmaculada Concepción ${ }^{14}$. Además, en la ciudad le esperaban los sevillanos Bernardo de Toro y Mateo Vázquez de Leca, que se habían encargado oficiosamente de la empresa concepcionista en la capital papal desde $1616^{15}$. El cardenal Borja informó desde Roma el veintitrés de octubre de 1618 de la llegada del nuevo embajador eclesiástico y de su primera audiencia con el papa Borghese ${ }^{16}$. Sin embargo, Pablo V, que apenas un año antes había concedido una victoria a los defensores de la pía opinión, emitió un breve en el que dejó clara su intención de no mudar nada en este asunto ${ }^{17}$.

Durante su estancia en Roma Antonio Trejo no estuvo ocioso en ningún momento y actuó en muy diversos campos para promocionar las pretensiones concepcionistas de la corona española. Pese a lo dudoso de su utilidad, Trejo compiló información de todo tipo para sustentar la doctri-

\footnotetext{
${ }^{4}$ Meseguer, 1955: 621-866 y Pou y Martí, 1931.

5 Gutiérrez, 1955: 7-480.

6 Tomassetti, 1867: 396

7 Tomassetti, 1867: 688 .

8 Tomassetti, 1867: 739-742.

9 Villalmonte, 1990: 137-153.

${ }^{10}$ Carta de Felipe III al conde de Castro, 25 de noviembre de 1611, Archivo General de Simancas (AGS), Estado, legajo 996, docs. 143-145. Volvería a instar al conde de Castro al año siguiente, tal y como se recoge en Carta de Felipe III al conde de Castro, 29 de febrero de 1612, AGS, Estado, legajo 998, s/f.

11 Carta de Antonio Trejo a Felipe III, 26 de junio de 1615, AGS, Estado, legajo 1001, doc. 260. Narra la llegada a la ciudad de fray Diego de Sicilia con los ornamentos y lámpara que el rey envía al Santo Sepulcro, y el gran impacto que su riqueza ha causado en esa corte.

${ }_{12}$ Así se reconoce en Carta de Felipe III a Antonio de Aróstegui, 8 de septiembre de 1618, AGS, Estado, legajo 1867 , doc. 278.

${ }^{13}$ Cartas de los cardenales Bonsi, Bellarmino, Lante, Campori, Toschi, Lancellotti, Montalto, Farnese, Mellini, Ginnasio, Crescenzi, Priuli, Varallo, de Siena, Aldobrandini y Giustiniani, s/d, AGS, Estado, legajo 1867, docs. 284 a 305.

${ }^{14}$ El propio Wadding sería el encargado de narrar por escrito las vicisitudes de la embajada de Antonio Trejo en Wadding, 1624.

15 Sobre Mateo Vázquez de Leca, véase Hazañas y La Rúa, 1918. Sobre Bernardo de Toro las informaciones existentes han sido publicadas de manera fragmentaria.

16 Carta del cardenal Borja a Felipe III, 23 de octubre de 1618, AGS, Estado, legajo 1867, doc. 281.

17 Breve de Pablo V (traducción), 21 de noviembre de 1619, AGS, Estado, legajo 1867, docs. 288 y 289.
} 
na. Así, estuvo al tanto de algunas intervenciones milagrosas vinculadas a la Inmaculada Concepción como la del canónigo Mulet en Manresa, cuyo proceso le fue enviado por la Real Junta de la Inmaculada en $1618^{18}$. Igualmente, Mateo Vázquez de Leca y Bernardo de Toro le hicieron entrega de la transcripción de los textos del Sacromonte de Granada, supuesto hallazgo arqueológico que podría haber dotado al concepcionismo de soporte bíblico ${ }^{19}$. Trejo intentó también controlar la propaganda impresa en torno al misterio y en 1619 consiguió, asistido por Luke Wadding, que se prohibiera el influyente volumen maculista de Vincenzo Bandelli ${ }^{20}$. Igualmente, el embajador se vinculó con la difusión de los escritos de sor Juana de la Cruz, cuya biografía fue tempranamente empleada como soporte de la doctrina de la Inmaculada Concepción ${ }^{21}$. La notable autoridad del libro de Antonio Daza sobre la monja franciscana explica las numerosas ediciones y traducciones del mismo que se realizaron a partir de 1610 en España e Italia ${ }^{22}$. Sin embargo, y probablemente debido a esa misma autoridad, en Roma se desató una notable oposición cuando Antonio Trejo intentó imprimir el texto en la capital papal23.

Al igual que Antonio Trejo se ocupó de la promoción de textos vinculados con la doctrina de la Concepción, también la imagen del misterio fue un elemento central durante su estapa romana. Así, en 1619 los agentes españoles para la causa de la Concepción, encabezados por Antonio Trejo, Luke Wadding y Bernardo de Toro, pusieron en circulación en Roma medallas con una clara intención de promocionar este culto ${ }^{24}$. En una de sus caras se mostraban el cáliz y la hostia acompañados por las palabras "Alabado sea el Santísimo Sacramento" y en la otra a la Virgen Inmaculada acompañada de la leyenda "Concebida sin pecado original". La iniciativa remitía a una acción del papa León X, quien un siglo antes había concedido indulgencias a "la imagen de la Concepción de Nuestra Señora que se ha de traer en un círculo redondo de metal cualquiera que sea, vestida de los rayos del Sol, coronada de estrellas, con la Luna a los pies y el cordón de San Francisco alrededor" 25 . Sin embargo, pese al decreto favorable de Pablo V en 1617, la acuñación de estos metales desató una agria polémica y las medallas concepcionistas fueron confiscadas ${ }^{26}$. La documentación de la Real Junta, siguiendo la información proporcionada por Luke Wadding, recoge que el diecinueve de noviembre de 1619 el maestro del Sacro Palacio inspeccionó las oficinas de orfebres y medallistas de Roma y destruyó muchos millares de estas acuñaciones ${ }^{27}$.

Pese a sus esfuerzos, las gestiones del obispo Trejo no consiguieron ningún avance significativo para la pía opinión y la Real Junta solicitó su regreso en $1619^{28}$. El Consejo de Estado recomendó en abril la vuelta del obispo de Cartagena, y en junio, desde la ciudad portuguesa de Almada, se le instó a regresar en cuanto el nuevo embajador ordinario llegara a Roma ${ }^{29}$. La indisposición papal ante la segunda embajada concepcionista de la monarquía fue patente. El propio Trejo, en carta enviada el veintinueve de febrero de 1619, denunció que la animadversión del pontífice derivó de los informes enviados a Roma por el nuncio Caetani ${ }^{30}$. Estos declaraban

${ }^{8}$ Archivo Histórico Nacional, Madrid (AHN), Consejos, legajo 2738, fol. 35v.

19 Carta de Bernardo de Toro y Mateo Vázquez de Leca a Pedro de Castro, 6 de enero de 1620, Biblioteca Nacional de España, Madrid (BNE), MSS/4011, fol. 135r. La obra seminal acerca de los hallazgos del Sacromonte es Kendrick, 1960. Véanse, entre las últimas aportaciones, Harris, 2007 y García-Arenal, 2010.

${ }^{20}$ AHN, Consejos, legajo 3752, fol. 105v.

${ }^{21}$ Daza, 1610.

22 Por ejemplo Daza, 1620.

23 Wadding, 1624: 335.

24 Stratton, 1989: 66-67.

${ }_{25}$ Sumario de las indulgencias de la Purísima Concepción de Nuestra Señora, concedidas por Nuestro muy Santo Padre León X, s/d, BNE, MSS/4011, fol. 219r.

${ }^{26}$ El largo proceso documentado en Pou y Martí, 1931: 166-178.

27 AHN, Consejos, legajo 3752, fols. 113r-113v.

${ }^{28}$ En AHN, Consejos, legajo 2738, fols. 42r-42v, se recoge el informe de la Real Junta de nueve de abril de 1619 en el que se culpabiliza al obispo Trejo de la desafección del pontífice y se insta a que vuelva a España.

${ }_{29}$ Consulta al Consejo de Estado, 18 de abril de 1619, AGS, Estado, legajo 1867, doc. 277, y Consulta al Consejo de Estado, 1 de junio de 1619, AGS, Estado, legajo 1867, doc. 276.

${ }^{30}$ AHN, Consejos, L. 2738, fols. 39v-40r. 
que no era el rey Felipe III quien profesaba devoción por el misterio de la Concepción, sino "su alteza de las Descalzas", a la sazón sor Margarita de la Cruz ${ }^{31}$. Sin embargo, parece que el motivo fundamental de la marcha de Trejo en 1620 fueron las desavenencias con el embajador duque de Alburquerque, que se negó a compartir la dignidad que le confería su misión diplomática oficial $^{32}$. Casi dos años después del regreso de Trejo a España, en 1622, Gregorio XV Ludovisi publicó un nuevo decreto favorable al misterio, el Sanctissimus, que prohibió cualquier manifestación, pública o privada, en contra de la doctrina de la Inmaculada Concepción. Aunque el obispo de Cartagena no fue directo responsable del éxito concepcionista, Trejo escribió inmediatamente a Roma y felicitó a Bernardo de Toro y Mateo Vázquez de Leca por su triunfo ${ }^{33}$.

\section{La capilla de la Inmaculada Concepción en la Catedral de Murcia}

Una vez finalizada su embajada concepcionista, Antonio Trejo siguió trabajando por la doctrina de la Inmaculada Concepción desde su diócesis de Cartagena. En Murcia, hizo pronunciar el voto de defensa de la pía opinión a todo el sínodo diocesano reunido en la sede episcopal el veintiocho de mayo de $1623^{34}$. En este sínodo se impuso, además, la prohibición de detentar cualquier cargo eclesiástico a aquellos que no hubieran jurado la defensa de la Inmaculada Concepción, asegurando de esta manera la fidelidad de toda la diócesis. El Ayuntamiento de Murcia se adhirió inmediatamente al voto concepcionista y decretó la celebración de solemnes fiestas para extender el fervor a toda la ciudad ${ }^{35}$. Sin embargo, la inmersión en la proclamación de la doctrina pía no se limitó a los juramentos, sino que al poco tiempo se solicitó el patronazgo de la Inmaculada Concepción para la Catedral de Murcia y para todo el reino. Trejo llegó, incluso, a ofrecer indulgencias a todos aquellos religiosos que pronunciaran la frase "Alabado sea el Santísimo Sacramento y la Purísima Concepción de la Virgen Santa María” al comenzar la misa ${ }^{36}$.

Además de difundir el voto concepcionista, tras llegar a Murcia Antonio Trejo empleó estrategias de promoción de la doctrina similares a las puestas en práctica durante su embajada. Así, en 1627 Trejo escribió a Roma a Bernardo de Toro acerca de la conveniencia de imprimir en España el libro que había escrito Luke Wadding sobre su misión en la capital papal ${ }^{37}$. Poco después, en 1629, el obispo escribió de nuevo a Toro informándole de que, tras unas últimas adiciones, un libro del concepcionista Juan Bautista Poza estaba listo para ser llevado a la imprenta ${ }^{38}$. Sin embargo, de entre todas las acciones emprendidas por Trejo para promocionar la doctrina de la Concepción, la más deslumbrante fue la construcción del magnífico trascoro marmóreo de la Catedral de Murcia, una formidable capilla dedicada a la Inmaculada Concepción con la imagen apocalíptica de María en el centro [fig. 1].

Antonio Trejo había propuesto en 1623 al cabildo encargarse de la decoración del trascoro catedralicio creando una suntuosa obra de mármoles y jaspes que pensaba dedicar a la Inma-

\footnotetext{
31 Véase, acerca de las implicaciones de las Descalzas y de sor Margarita de la Cruz en esta fase del periplo concepcionista y sus motivaciones Ruiz-Gálvez Priego, 2006: 291-310.

32 Pou y Martí, 1931: 147-153.

33 Carta de Fr. Antonio de Trejo, obispo de Cartago, a D. Mateo Vázquez y Dr. de Toro, 12 y 19 de julio de 1622 , Biblioteca de la Universidad de Granada, caja 2, legajo 65, fols. 185r-186v.

34 Molinero, 1955: 1057-1071.

35 López García, 2005: 119-138.

36 Molinero, 1955: 1057-1071, especialmente la p. 1064.

37 Carta de Antonio Trejo a Bernardo de Toro, 22 de septiembre de 1627, Archivo de la Obra Pía de España en Roma (AOPER), Códices de la Embajada de España ante la Santa Sede, Epistolario de Bernardo de Toro, ms. 436, fols. 138r-139r.

38 Carta de Antonio Trejo a Bernardo de Toro, 20 de abril de 1629, AOPER, Códices de la Embajada de España ante la Santa Sede, Epistolario de Bernardo de Toro, ms. 436, fols. 408r-409v. Sobre Poza, véase Lavenia, 2010: 179211 y Moreno Martínez/Peña Díaz, 2011: 159-170.
} 


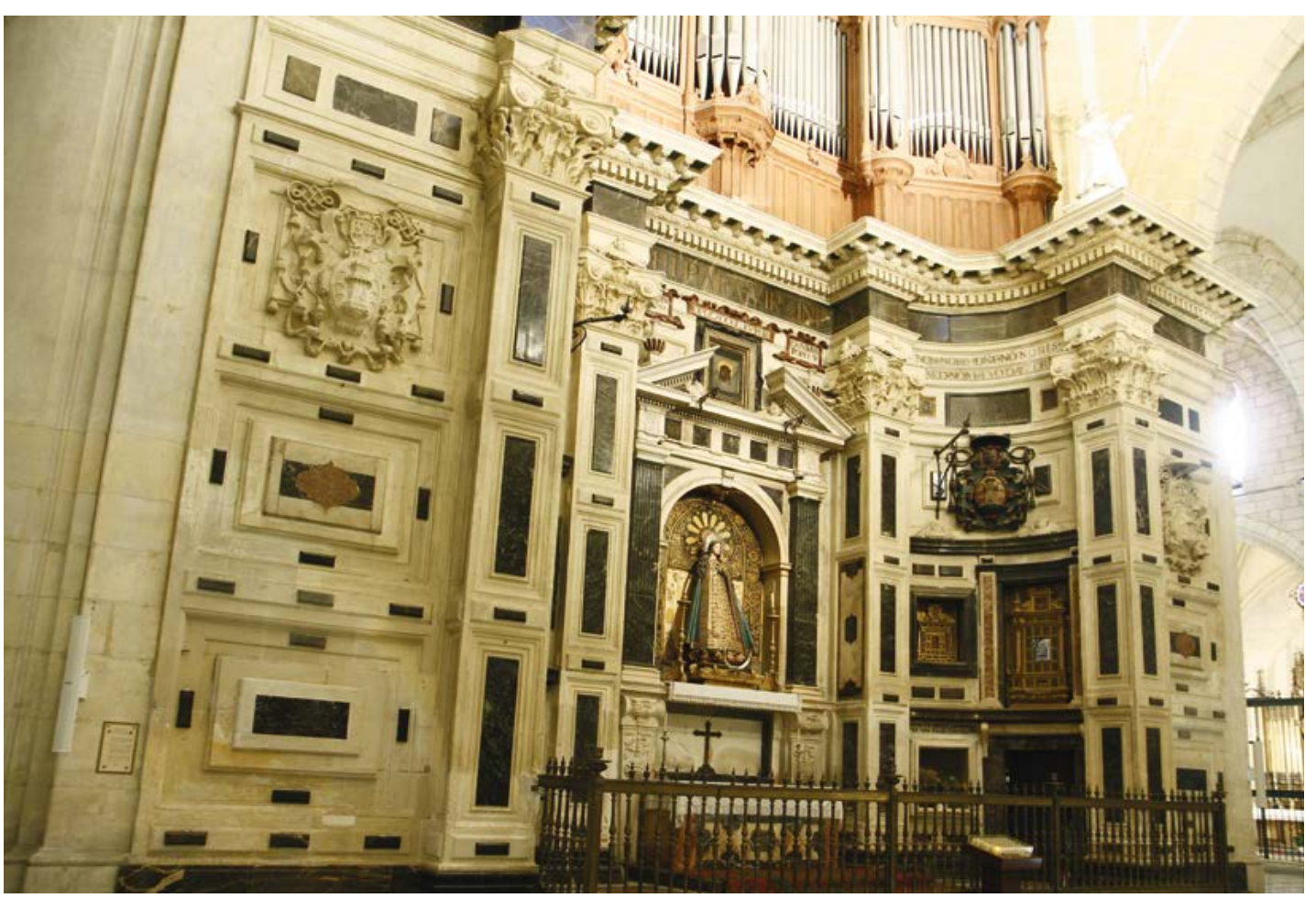

Fig. 1. Capilla de la Inmaculada Concepción de la Catedral de Murcia. 1623-1627.

culada Concepción y a su propio enterramiento ${ }^{39}$. En 1625 el racionero de la Catedral, Juan Agustín de Móstoles, vendió el trascoro a Antonio Trejo por cuatrocientos ducados, al tiempo que el obispo se ofreció a gastar cuatro mil más en la edificación ${ }^{40}$. En aquel momento Antonio Trejo poseía ya una traza de la obra y las piedras duras que iban a emplearse en su construcción estaban depositadas en el claustro de la Catedral ${ }^{41}$. Ese mismo año se realizó el acto de cesión del trascoro y se dio licencia a Trejo para colocar sus armas en la capilla, algo que, efectivamente, haría ${ }^{42}$.

En una copia de escrituras de la capilla del trascoro de la Catedral de Murcia conservada en el archivo catedralicio se detallan las intenciones de Antonio Trejo en $1625^{43}$. Aquí se recogen las intervenciones anteriores del obispo en la Catedral: las puertas de la capilla mayor, el sagrario y la ayuda para dorar y colocar en la capilla mayor las imágenes de san Fulgencio, san Leandro, san Isidoro y santa Florentina ${ }^{44}$. En estos momentos se acordó que la capilla se construyera de pilar a pilar de la Catedral ocupando la totalidad de la nave central, más las puertas en los pilares

39 Archivo de la Catedral de Murcia (ACM), Actas Capitulares, caja 11, libro 13, fols. 112r-112v. También recogido en Testimonios de actas capitulares en razón de la obra del trascoro y capilla mayor y entierro del Ilustrísimo Señor Obispo Trejo, s/d, ACM, legajo 186, doc. 22.

40 Venta del trascoro de la Catedral de Murcia, 16 de junio de 1625, Archivo General de la Región de Murcia (AGRM), Protocolos Notariales, Pedro Fernández de Reolid, NOT. 1132, fols. 416r-419v.

${ }^{41}$ Escritura de cesión de derecho de enterramiento en el trascoro de la Catedral al obispo Trejo por parte del cabildo, representado por el racionero Juan Agustín de Móstoles, 16 de junio de 1625, ACM, legajo 186, doc. 23.

42 Cesión del trascoro de la Catedral de Murcia, 21 de marzo de 1625, AGRM, Protocolos Notariales, Pedro Fernández de Reolid, NOT. 1132, fols. 451r-453v.

${ }^{43}$ Copia de escrituras de la capilla del trascoro de la Catedral de Murcia, 16 de junio de 1625, ACM, legajo 186, doc. 23.

${ }^{44}$ Sobre la reforma del presbiterio catedralicio, véase Nadal Iniesta, 2015: 197-211, y Nadal Iniesta, 2018: 128-150. 
para subir al órgano, y una de las capillas colaterales que serviría como sacristía ${ }^{45}$. En 1625 se concedieron a Trejo ocho sepulturas en la capilla del trascoro para él mismo y los miembros de su familia. En este mismo documento el cabildo recogió una serie de testimonios de personas que habían visto la traza y las piedras duras acumuladas por el obispo y que fueron, todos ellos, favorables a la construcción de la capilla de la Inmaculada. Destacó, entre los avales, el del notario Diego de Funes y Mendoza, quien subrayó la dotación de reliquias de santos, retablos y cuadros prevista por Trejo y afirmó que "el dicho trascoro será una de las cosas buenas que hoy hay en ninguna iglesia Catedral de España".

Las obras de la capilla de la Inmaculada Concepción de la Catedral de Murcia avanzaron a buen ritmo bajo la supervisión del mayordomo de Trejo, José Lucas Ximénez, a quien el obispo dio poderes para encargarse de la edificación ${ }^{46}$. Pese a que se desconoce el nombre del tracista de la obra, en su ejecución participaron los canteros Miguel de Madariaga, Alonso de Toledo y Bartolomé Sánchez, el escultor Bartolomé de Salazar, los albañiles Juan Fernández, Jerónimo Pérez y Domingo Villanueva y el rejero Andrés de Ortigosa ${ }^{47}$.

En 1626 el cabildo de la Catedral de Murcia emprendió acciones contra Trejo por una obra que, según los canónigos, había excedido con creces el planteamiento inicial. Las quejas afirmaron que el obispo había tomado veintiséis sepulturas en lugar de las ocho inicialmente previstas ${ }^{48}$. Además, en el traslado de los pleitos entre cabildo y obispo se mezclaron las quejas por la obra del trascoro, que, según los canónigos, era muy dañina para la Catedral, amenazaba ruina por estar mal cimentada y dejaba el coro sin luz ni ventilación, con muestras de un enfrentamiento soterrado anterior ${ }^{49}$. Así, el cabildo se quejó de que, cuando se había reformado el presbiterio unos años antes, Trejo había retirado las armas de Alfonso X para poner las suyas y se había adjudicado la obra mediante una inscripción que rezaba "Esta obra y adorno de capilla mandó hacer a su costa fray Antonio de Trejo obispo de la Santa Iglesia siendo fabriquero el maestro Juan Agustín de Móstoles racionero. Año de 1623". Claramente, los regentes de la Catedral de Murcia estaban indignados tanto por las enormes dimensiones de la capilla de la Inmaculada, como por la omnipresencia de las armas del obispo Trejo en su iglesia.

Pese a que resulta complejo desentrañar la verdad en el conflicto entre obispo y cabildo, la situación se enconó de tal manera que no parecía tener solución. En el centro de la disputa se encontraba el mayordomo de Trejo, al que los capitulares se habían negado a dar el oficio de pertiguero. A partir de aquí, los canónigos se quejaron de que el obispo manejaba los tribunales a su antojo y en contra de ellos y de que estaba difundiendo libelos acerca de que tenían relaciones con mujeres ${ }^{50}$. Enfadado por los desaires de Trejo y dispuesto a demostrar su poder sobre el edificio de la Catedral, en septiembre de 1626 el cabildo expulsó a los canteros del obispo, cerró las puertas del templo y confiscó todas las llaves ${ }^{51}$. La ira de Antonio Trejo llegó a tal punto que, según recogen las actas capitulares, afirmó que en la designación de oficios catedralicios su voto contaba más que el de todo el cabildo junto y amenazó a los canónigos con excomunión mayor ${ }^{52}$.

El nuncio papal en Madrid mandó detener las obras de la capilla de la Inmaculada Concepción a finales de $1626^{53}$. Entonces, los maestros de albañilería Juan Martínez y Cebrián Hernández

45 La concesión de dicha capilla a Trejo el 31 de julio de 1626 en ACM, Actas Capitulares, caja 11, libro 13, fol. 344r.

46 Poder de Antonio Trejo a José Lucas Ximénez, 21 de abril de 1625, AGRM, Protocolos Notariales, Pedro Fernández de Reolid, NOT. 1132, fols. 462r-462v.

47 Sánchez Rojas-Fenoll, 1987: 1535-1545, especialmente las pp. 1538-1539.

48 Memorial de los incumplimientos de Trejo en la obra del trascoro, s/d, ACM, legajo 186, doc. 24.

49 Traslado de los puntos que se advirtieron en los pleitos con el señor obispo Trejo sobre las armas de la capilla mayor y obra del trascoro, s/d., ACM, legajo 186, doc. 21. Los incumplimientos de Trejo recogidos, también, en Memorial de los incumplimientos de Trejo en la obra del trascoro, s/d, ACM, legajo 186, doc. 24.

${ }^{50}$ El 25 de septiembre de 1626. ACM, Actas Capitulares, caja 11, libro 13, fols. 363v-364v.

51 El 25 de septiembre de 1626. ACM, Actas Capitulares, caja 11, libro 13, fols. 364v-365r.

52 El 14 de enero de 1627. ACM, Actas Capitulares, caja 11, libro 14, fols. 6r-6v.

53 Sentencia de Juan Bautista Pamphili, nuncio de Urbano VIII en España, 5 de octubre de 1626, ACM, legajo 186, doc. 25 , fols. $1 \mathrm{r}-2 \mathrm{r}$. 


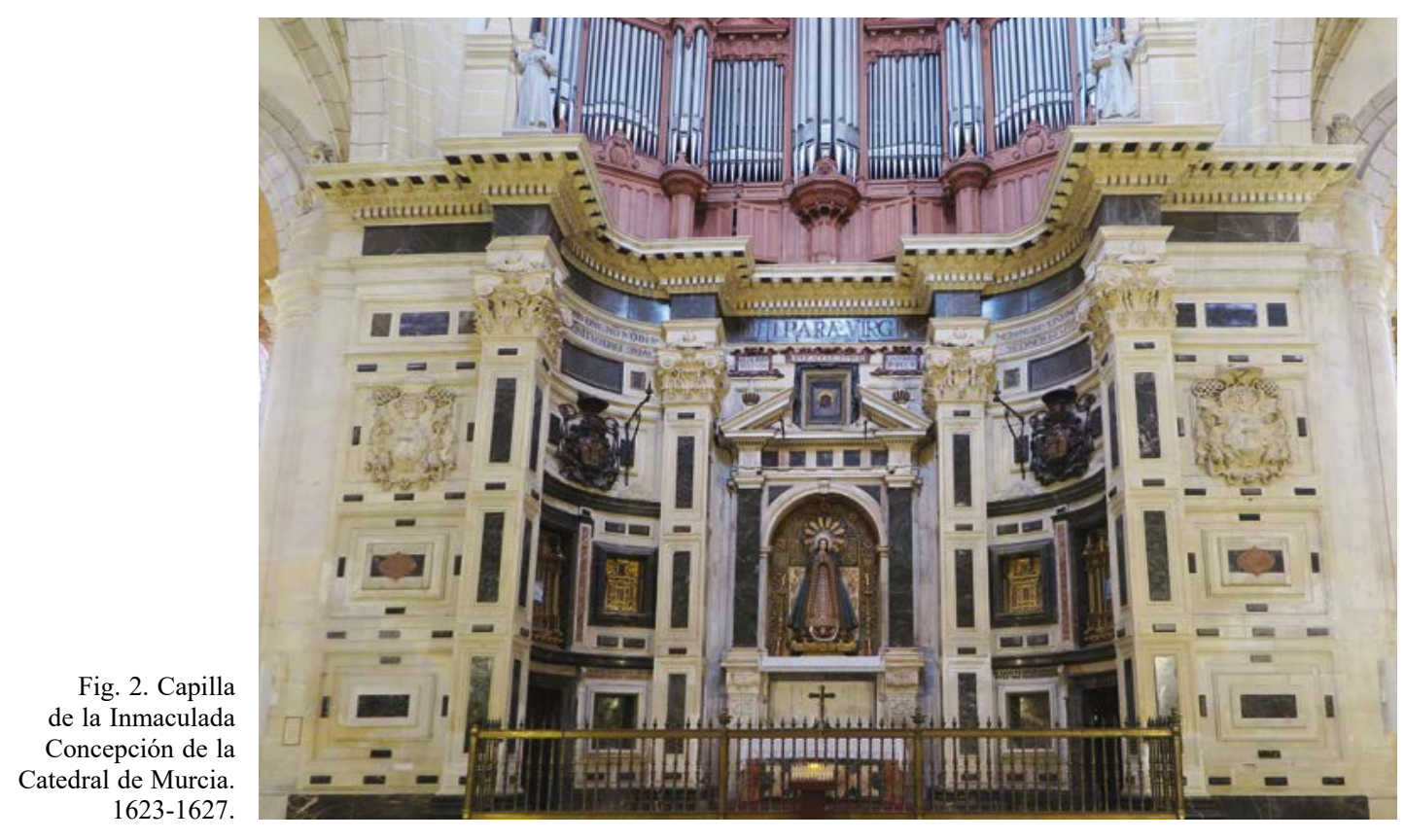

determinaron que era necesario añadir dos pilares a la obra para asegurarla ${ }^{54}$. Finalmente, pese a que "los grandes maestros que para su obra tenía su señoría" no estaban de acuerdo con las modificaciones propuestas, a principios de 1627 la obra se encontraba terminada ${ }^{55}$. En enero de 1627 se recogieron los testimonios de una serie de artífices sobre la obra finalizada del trascoro que habían tomado parte en la ejecución material de la misma ${ }^{56}$. Estos fueron el carpintero Antonio Martínez, los maestros de cantería Sebastián Pérez de Arteaga y Miguel de Madariaga y el maestro de rejería Andrés de Arteaga.

La obra concluida por voluntad de Antonio Trejo en 1627 es una formidable pantalla de mármoles de cinco calles separadas por cuatro pilastras proyectantes de orden compuesto. ${ }^{57}$ Las tres calles centrales se retranquean creando una planta cóncava que enmarca y realza el altar central dedicado a la Inmaculada Concepción [fig. 2]. Pese a su riqueza, la composición de la capilla de la Inmaculada Concepción de la Catedral de Murcia no resulta del todo satisfactoria: los tres cuerpos no mantienen las mismas líneas de cornisas en las cinco calles, el conjunto carece de cierre arquitectónico en los extremos y en las calles intermedias se acumulan relicarios, escudos o esculturas que fragmentan el muro de manera un tanto desordenada. Todos estos errores parecen alejar la obra del trascoro del control de un arquitecto o del empleo de una traza rectora seguida fielmente. La traza existió, pues así se reconocía en 1625, pero fue seguramente adaptada y modificada debido a los pleitos con el cabildo. Así se desprende de la declaración de Antonio Martínez en 1627, ya terminada la obra, en la que el carpintero afirmó que Trejo había ordenado que se redujera la altura de la capilla con respecto a lo estipulado en la traza, "aunque perdiese las proporciones que el arte pedía" 58 .

54 Declaración ante el notario Fernando García Valverde de los maestros de albañilería Jusepe Martínez y Cebrián Hernández, 15 de enero de 1627, ACM, legajo 186, doc. 25, fols. 22r-22v.

55 Presentación por el fiscal general del obispado de las preguntas que se han de formular a los testigos en el pleito del trascoro, 18 de enero de 1627, ACM, legajo 186, doc. 25, fols. 23r-33r.

${ }^{56}$ Presentación por el fiscal general del obispado de las preguntas que se han de formular a los testigos en el pleito del trascoro, 18 de enero de 1627, ACM, legajo 186, doc. 25, fols. 23r-33r.

57 Además de las ya citadas, véase, sobre la obra y capilla del trascoro, las reflexiones de Rivas Carmona, 1994 : 123-125, Rivas Carmona, 2001: 187-204, y Nadal Iniesta, 2018, 150-159.

58 Testimonio de Antonio Martínez, 18 de enero de 1627, ACM, legajo 186, doc. 25, fol. 24v. 


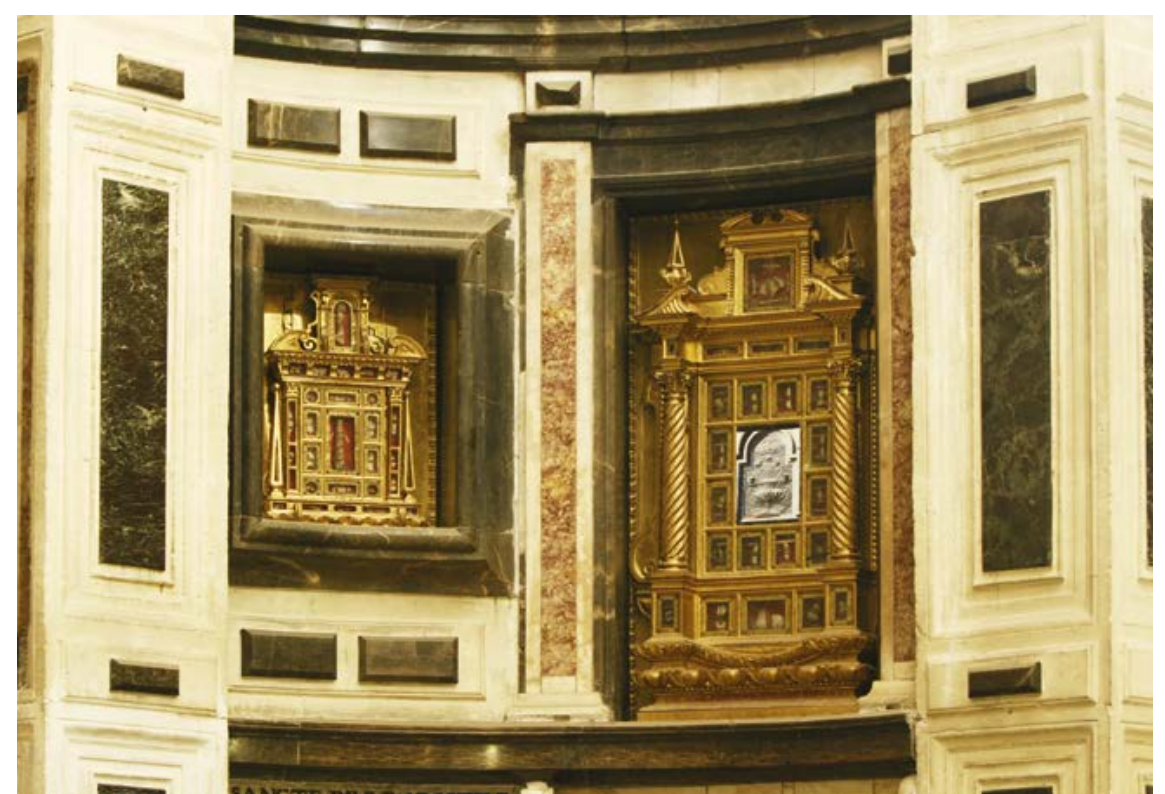

Fig. 3. Juan Bautista Estangueta, Relicarios, 1623-1627. Capilla de la Inmaculada Concepción de la Catedral de Murcia.

Sin el achatado de las proporciones, con un cierre adecuado de los extremos del trascoro y con las calles intermedias más espaciosas y mejor compuestas la obra habría sido bien distinta, como debió serlo su traza. Si los artífices principales de la construcción fueron los vecinos de Murcia Miguel de Madariaga, Alonso de Toledo, Bartolomé Sánchez, Bartolomé de Salazar, Juan Fernández, Jerónimo Pérez y Domingo Villanueva, el nombre del tracista de la capilla sigue siendo, de momento, una incógnita. La traza de la obra, aunque muy desfigurada por las modificaciones derivadas de los pleitos entre el obispo Trejo y el cabildo, se ha relacionado tradicionalmente con el entallador Diego Sánchez de Segura ${ }^{59}$. Sin embargo, el diseño original podría también proceder del foco clasicista gestado en torno a la construcción del santuario de la Vera Cruz en Caravaca y el arquitecto fray Alberto de la Madre de Dios ${ }^{60}$.

El ajuar original que vistió la obra arquitectónica del trascoro de la Catedral de Murcia puede ser rastreado a través de los inventarios de bienes de la capilla de la Inmaculada Concepción. El primer inventario conservado, muy escueto, se redactó en 1644, pocos años después del fallecimiento de Antonio Trejo ${ }^{61}$. Aquí se reseñan, además de piezas textiles y de orfebrería, un cuadro de la Verónica que todavía hoy corona la imagen mariana titular, los retratos de Antonio y Gabriel Trejo, dos Crucificados y varios Niños de escultura. Aunque no se nombra, evidentemente la escultura de la Inmaculada Concepción presidía ya el altar, pues se registran varios pagos al pintor Francisco Gilarte por cortinas-bocaporte para la estatua ${ }^{62}$. Ya entonces debía haber dos bustos de san Pedro y san Pablo en los nichos inferiores de la capilla, pues en 1689 se documenta el pago por retocar su policromía ${ }^{63}$.

En 1696 se elaboró un nuevo inventario en el que, junto a las piezas enumeradas en 1644, se señala la presencia de cinco relicarios que, con toda seguridad, pertenecen al diseño original ideado por Antonio Trejo ${ }^{64}$. Como se puntó, ya en 1625 se vinculó la construcción del trascoro

59 Crespo García, 1969: 83-108.

${ }^{60}$ Segado Bravo, 1995: 261-268.

61 Inventario de los bienes de la capilla de la Concepción, 1 de enero de 1644, ACM, legajo 185, doc. 21, fols. 50r-51v. Este inventario es posterior a la muerte de Trejo en 1635 y al expolio de sus bienes. Sobre el largo proceso del expolio, con particular hincapié en el pontifical del obispo, véase Alegría Ruiz, 2019: 1-20.

${ }^{62}$ Libro de cuentas de la capilla de la Concepción, 1659-1660, ACM, legajo 185, doc. 21, fols. 40r y 41r.

${ }^{63}$ Libro de cuentas de la capilla de la Concepción, 1689, ACM, legajo 185, doc. 21, fol. 94r.

${ }^{64}$ Inventarios de bienes de la capilla de la Concepción, 1 de enero de 1696, ACM, legajo 207, doc. 26, fols. 22r-25v. 


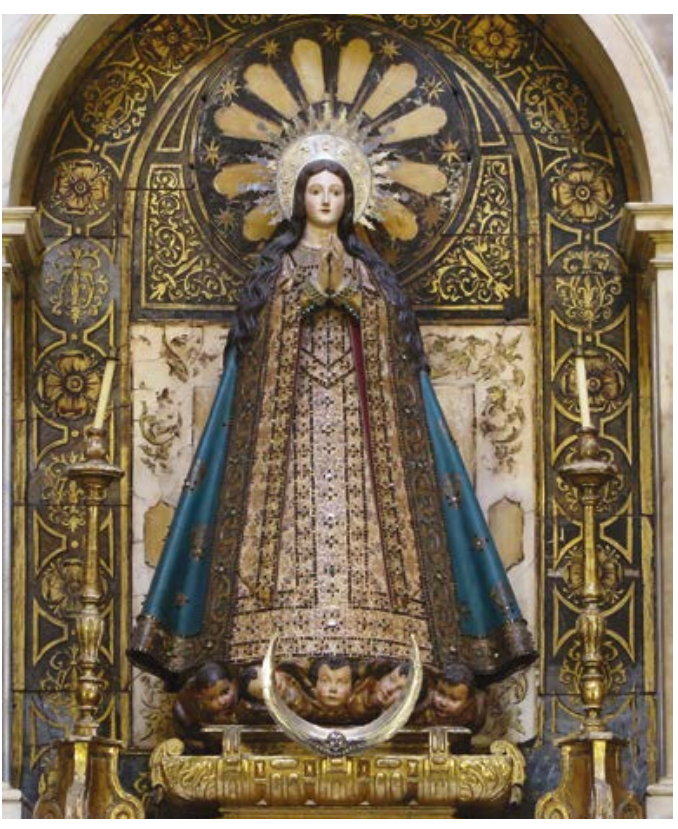

Fig. 4. Antonio de Herrera Barnuevo, Inmaculada Concepción, 1626-1627. Capilla de la Inmaculada Concepción de la Catedral de Murcia. concepcionista con la acumulación de reliquias $^{65}$. Los relicarios reseñados en 1696 son dos grandes retablos sobre las puertas de la capilla, dos menores al lado de estos y una quinta teca en forma de pirámide, no conservada, en el centro del altar. Los cuatro relicarios que se alojan en las hornacinas que ocupan el segundo cuerpo de las calles intermedias de la capilla de la Inmaculada Concepción han sido atribuidos al retablista murciano Juan Bautista Estangueta y se adecúan a los estilemas de la tercera década del siglo XVII ${ }^{66}$ [fig. 3].

El inventario de la capilla redactado en 1756 , pese a cometer algunos errores, es todavía más minucioso ${ }^{67}$. Además de la escultura de la Inmaculada Concepción, se constata la presencia de dos bustos de san Pedro y san Pablo, en madera, que sustituían a los originales en piedra. De los relicarios, se describe que uno porta la imagen del Ángel Custodio en el centro y otro la de san Antonio, mientras que del central se afirma que tiene forma de tabernáculo y está colocado en un nicho transparente encima de la imagen de la Inmacula-

da. A los retratos de Antonio y Gabriel Trejo se añade, en estos momentos, el de Fernando de la Cerda y Trejo, marqués de la Rosa. Aquí se constata, además, que originalmente las esculturas de piedra que remataban la construcción eran cuatro, de las que hoy en día solo se conservan las de san Francisco y san Antonio de Padua.

La documentación conservada en Murcia no señala el autor de la pieza artística más relevante de la capilla del trascoro, la escultura titular de la Inmaculada Concepción [fig. 4]. Sin embargo, su factura la vincula con el sevillano Bernardo de Toro, con quien Antonio Trejo siguió manteniendo una estrecha relación tras su vuelta de Roma. De hecho, Toro se alojó hasta la muerte del cardenal en la residencia romana de Gabriel Trejo, hermano del obispo de Cartagena ${ }^{68}$. Incluso al final de la vida del obispo, Toro le envió desde Roma una imagen de la Madonna Advocata, icono titular de la cofradía de la Concepción en la basílica romana de San Lorenzo in Damaso $^{69}$. Por todo ello, no es de extrañar que, para dotar de una imagen adecuada a la capilla murciana de la Concepción, Antonio Trejo recurriera a la red de contactos de su amigo Bernardo de Toro.

En enero de 1627 Dionisio Esquivel, canónigo de la Catedral, y Juan Agustín de Móstoles, racionero, declararon que Trejo estaba a la espera de la imagen de la Inmaculada Concepción que debía llegar desde Madrid ${ }^{70}$. En los meses anteriores un anónimo agente de Bernardo de Toro le había escrito desde Madrid para contarle que finalmente había conseguido que se realizara la escul-

65 Testimonio de Diego de Funes y Mendoza, 6 de abril de 1625, ACM, legajo 186, doc. 23.

66 Sánchez-Rojas Fenoll, 1981: 221-255, especialmente las pp. 234-235.

${ }^{67}$ Inventarios de bienes de la capilla de la Concepción, 1 de enero de 1756, ACM, legajo 207, doc. 26, fols. 1r-5v.

${ }^{6}$ Carta de Enrique de Guzmán a Bernardo de Toro con copias de las cartas de Enrique de Guzmán a Felipe IV y el duque de Alcalá, 6 de julio de 1630, AOPER, Códices de la Embajada de España ante la Santa Sede, Epistolario de Bernardo de Toro, ms. 436, fols. $586 \mathrm{r}-587 \mathrm{v}$.

${ }^{69}$ Carta de Antonio Trejo a Bernardo de Toro, 23 de octubre de 1635, AOPER, Códices de la Embajada de España ante la Santa Sede, Epistolario de Bernardo de Toro, ms. 436, fols. 555r.

70 Presentación por el fiscal general del obispado de las preguntas que se han de formular a los testigos en el pleito del trascoro, 18 de enero de 1627, ACM, legajo 186, doc. 25, fols. 23r-33r. 
tura de la Inmaculada Concepción ${ }^{71}$. Al parecer "el amigo de Sevilla" había intentado en tres ocasiones llevar a cabo la imagen sin éxito y, finalmente, se le había encargado al escultor del rey (entonces Antonio de Herrera Barnuevo) ${ }^{72}$. El amigo sevillano se trataba, probablemente, de Juan Martínez Montañés, imaginero del círculo de Bernardo de Toro $^{73}$. Y el rechazo de su escultura por tres veces remite a consideraciones de tipificación de la imagen barajadas por los concepcionistas sevillanos ${ }^{74}$. La estatua no se hizo esperar, y el diez de febrero de 1627 el obispo Antonio Trejo informó a Toro desde Murcia de que la imagen de la Inmaculada Concepción se había colocado en su capilla ${ }^{75}$.

\section{Devoción, muerte y memoria}

Pese a la vinculación personal de Antonio Trejo con la doctrina de la Inmaculada Concepción, las intenciones del embajador concepcionista de Felipe III al construir una formidable capilla en el trascoro murciano fueron mucho más allá de la simple devoción, y se orientaron hacia la creación de un espacio capaz de fijar su recuerdo tras la muerte. Trejo no debía ser ajeno al concepto de fama póstuma y memoria, pues entre sus bienes se inventarió un conjunto pictórico con los Nueve de la Fama, paradigma visual de la victoria del ser humano sobre el olvido ${ }^{76}$. Para vencer al inexorable paso del tiempo, Trejo hizo de la capilla de la Inmaculada Concepción la única heredera de todos sus bienes ${ }^{77}$. Además, nombró patrón de la fundación a su hermano Francisco Trejo y Monroy, marqués de la Rosa, y fundó cuatro capellanías ocupadas por Joan Pagán, Pedro Torrente, Alonso de Villena y Diego Reinoso. Las intenciones del obispo fueron, desde luego, percibidas por sus contemporáneos, y ya Alonso de Mergelina y Montejo, inmediatamente después de la conclusión de la obra, fio la inmortalidad de Trejo a la construcción de esta capilla que le aseguraría la victoria sobre el paso del tiempo ${ }^{78}$.

Desde el inicio del proceso constructivo de la capilla de la Inmaculada Concepción Antonio Trejo vinculó la obra con el mantenimiento de su propia memoria, y para que esta perviviera solicitó al cabildo el permiso para poner sus "armas y bultos y rótulos en la parte que conviniere" y tener derecho de patronato y sepultura ${ }^{79}$. Su lápida aún puede verse en el pavimento de uno de los laterales del trascoro y, además, el primer inventario de la capilla, redactado en 1644, constata que en ella se conservaba un retrato del obispo y otro de su hermano el cardenal Gabriel Trejo $^{80}$. Pero, además, el mensaje memorial de la capilla, junto a las lápidas, escudos y retratos, se transmite a través de una serie de inscripciones latinas.

71 Carta a Bernardo de Toro, 24 de enero de 1626, AOPER, Códices de la Embajada de España ante la Santa Sede, Epistolario de Bernardo de Toro, ms. 435, s/f.

${ }_{72}$ Antonio de Herrera Barnuevo es el autor de las precedentes estatuas de la Inmaculada Concepción del convento de las Descalzas Reales de Madrid y de la Catedral de Segovia que son, sin embargo, mucho menos rígidas que la enviada a la Catedral de Murcia. Véase Ruiz Hernando, 1966: 650-671.

73 Véanse González Polvillo, 2009: 47-72 y Lleó Cañal, 2015: 201-217.

74 Tal y como se recoge en Pacheco, 1990: 575-577.

75 Carta de Antonio Trejo a Bernardo de Toro, 10 de febrero de 1627, AOPER, Códices de la Embajada de España ante la Santa Sede, Epistolario de Bernardo de Toro, ms. 436, fols. 26r-26v.

${ }^{76}$ Actos de la Reverenda Cámara Apostólica de lo que se debe del expolio del obispo Trejo y de la capilla de la Concepción del trascoro, 10 de febrero de 1642, ACM, legajo 186, doc. 43. Sobre el tipo iconográfico de los Nueve de la Fama, véanse Meyer, 1883: 45-54, Schroeder, 1971 y Sedlacek, 1997. Recientemente Gómez Frechina, 2019: 114135, ha profundizado en la producción de Pedro Orrente, pintor activo en Murcia en las primeras décadas del siglo XVII, sobre esta temática.

77 Copia del testamento de Antonio Trejo certificada por el notario Juan Prieto Alarcón, 4 de agosto de 1638, ACM, legajo 186, doc. 44.

78 Mergelina y Montejo, 1628: 8v-9r. doc. 23 .

79 Copia de escrituras de la capilla del trascoro de la Catedral de Murcia, 16 de junio de 1625, ACM, legajo 186,

80 Inventario de los bienes de la capilla de la Concepción, 1 de enero de 1644, ACM, legajo 185, doc. 21, fols. 50r-51v. Los retratos siguen apareciendo en el inventario de 1696, Inventarios de bienes de la capilla de la Concepción, 1 de enero de 1696, ACM, legajo 207, doc. 26, fols. 22r-25v. 


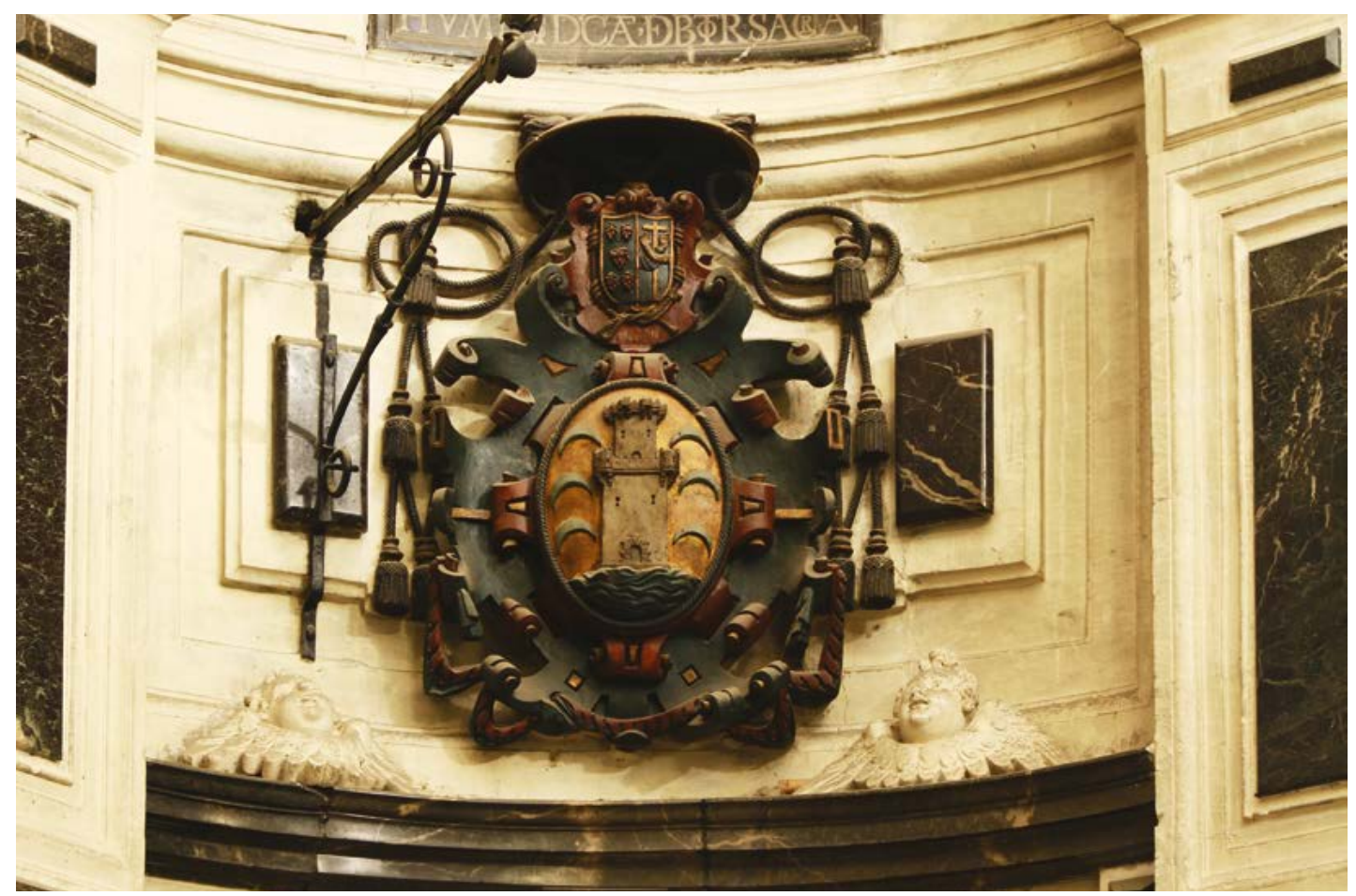

Fig. 5. Armas del obispo fray Antonio Trejo, 1623-1627. Capilla de la Inmaculada Concepción de la Catedral de Murcia.

En la calle central del trascoro marmóreo, ocupada por la escultura de la Inmaculada Concepción, el friso contiene el escrito que dedica la capilla a María ${ }^{81}$. Por debajo, tres cartelas exaltan el trofeo petrificado que esta capilla es del triunfo sobre el pecado original ${ }^{82}$. Sin embargo, las calles intermedias a izquierda y derecha de la hornacina central están dedicadas a los hermanos Gabriel y Antonio Trejo. Aquí se muestra, en el friso, un texto que reclama con humildad que la construcción del trascoro fue a mayor gloria de Dios y no de su patrocinador ${ }^{83}$. No obstante, el tamaño de los escudos de Antonio Trejo parece desmentir esta modestia [fig. 5]. Además, encima de ellos dos placas de mármol oscuro recuerdan a los coprotagonistas de la obra. A la izquierda de la Inmaculada Concepción, se enumeran los méritos de Gabriel Trejo como cardenal, arzobispo de Salerno, presidente del Consejo de Castilla y obispo de Málaga ${ }^{84}$. A la derecha, se reclama que Antonio Trejo fue general de los franciscanos, obispo de Cartagena y embajador de Felipe III ante Pablo V85.

Antonio Trejo ideó en la Catedral de Murcia un conjunto monumental en el que el recuerdo efímero de su persona se ligó de manera indisoluble a la doctrina que había marcado los últimos treinta años de su vida: la Inmaculada Concepción de la Virgen. Esta asociación no era algo nuevo en la España del siglo XVII, y otros, particularmente en el medio sevillano, ya habían ligado su propia memoria con la imagen mariana del misterio. Así, en 1612 Juan de Roelas pintó a la Inmaculada con Fernando de Mata para su tumba en el convento de la Encarnación ${ }^{86}$. La Inmaculada

81 DEIPARAE VIRGINIS.

82 REDDIMUS VOTUM, DE PECCATO ORIGINALI TRIUMPHATRICI y CANIMUS TROPHEUM.

83 NON NOBIS DOMINE NON NOBIS SED NOMINI TUO DA GLORIAM.

${ }^{84}$ GABR. S.R.E. PRESB. CARD, DE TREJO ARCHIEP, SALERN, EPISCOPUS MALACI SUPRAEM. CASTELLE PRAESES PRO IMMACULATA CONCEPT. ERIGEBAT IN TITULUM.

${ }^{85}$ FR. ANT. A TREJO GEN OR. S. FRAN. EPISCOPUS CARTH. ORATOR PHIL. III AD PAU V. PRO DEFINITIONE INMACULATAE CONCEPTIONIS HUMILISIMO DCAT. DEBOTOR SACRAT.

86 Jesús María, 1663: 35v-37r. 
con Miguel Cid fue pintada por Francisco Pacheco en 1619, probablemente para la sepultura del retratado ${ }^{87}$. En 1621 se pintó la imagen de María acompañada de Mateo Vázquez de Leca, concebida también para un contexto funerario ${ }^{88}$. Y un tercer lienzo de Pacheco, idéntico a los anteriores, representó a Bernardo de Toro en fechas muy similares ${ }^{89}$. El retrato de estos cuatro devotos sevillanos y la supervivencia de su recuerdo tras la muerte se ligó al triunfo de la devoción por la Inmaculada Concepción. Por ello, no es de extrañar que Antonio Trejo, que conocía bien a Bernardo de Toro y a Mateo Vázquez de Leca, ideara un marco similar para su descanso eterno.

En el trascoro de la Catedral de Murcia Antonio Trejo se aseguró de que su recuerdo perviviera mediante multitud de mecanismos. Tras asegurarse de que la diócesis y la ciudad pronunciaran el voto de defensa del misterio y de que la Catedral y el reino reconocieran a la Inmaculada Concepción como su patrona, el obispo creó una arquitectura grandiosa dedicada a esta doctrina. En ella, además de la imagen de la titular, a la que todos los murcianos estaban ya obligados a venerar, se ubicaron cinco relicarios que aumentaron el prestigio de la fundación y fomentaron la devoción de los fieles. El artefacto fue sacralizado y, en consecuencia, se sacralizó también a los dos hermanos cuya memoria, en escudos, inscripciones y retratos, custodiaba la capilla de la Inmaculada Concepción. Los hermanos Trejo se hicieron acompañar en la parte baja de las calles intermedias, no de manera casual, por los bustos de san Pedro y san Pablo coronados, respectivamente, por dos textos que ensalzan las figuras de ambos apóstoles ${ }^{90}$. Gabriel y Antonio Trejo parecen reclamarse, en el trascoro de la Catedral de Murcia, como los nuevos santos Pedro y Pablo de la Contrarreforma. Apóstoles de Dios y de una creencia, la de la Inmaculada Concepción de María. Los retratos de los hermanos Trejo se perdieron y la lápida del obispo resulta casi ilegible hoy en día. Sin embargo, el éxito de la doctrina de la Inmaculada Concepción aseguró la fama eterna del que fue, durante un tiempo, su embajador en Roma.

\section{BIBLIOGRAFÍA}

Alegría Ruiz, Francisco José (2019): "El pontificial del obispo fray Antonio de Trejo”. En: Tonos digital: Revista de estudios filológicos, 37, Murcia, pp. 1-20.

Bassegoda i Hugas, Bonaventura (1988): “Adiciones y complementos al catálogo de Francisco Pacheco”. En: Boletín del Museo e Instituto Camón Aznar, 31-32, Zaragoza, pp. 151-176.

Bassegoda i Hugas, Bonaventura (2016): "Algunas precisiones sobre Francisco Pacheco y la iconografía sagrada”. En: Muñoz Rubio, María del Valme/Cano Rivero, Ignacio (eds.): Pacheco. Teórico, artista, maestro (1564-1644). Sevi1la: Junta de Andalucía, pp. 37-47.

Crespo García, José (1969): "Fray Diego Sánchez de Segura, notable artista del siglo XVII". En: Murgetana, 30, Murcia, pp. 83-108.

Daza, Antonio (1610): Historia, vida y milagros, éxtasis y revelaciones de la bienaventurada Virgen Santa Juana de la Cruz, de la tercera Orden de San Francisco. Madrid: Luis Sánchez.

Daza, Antonio (1620): Istoria, vita, miracoli, estasi, e reuelazioni della ben'aunenturosa vergine suor Giovanna della Croce, del Terzo Ordine del nostro serafico padre San Francesco. Nápoles: Scipione Bonino.

García-Arenal, Mercedes (2010): Un oriente español: Los moriscos y el Sacromonte en tiempos de la Contrarreforma. Madrid: Marcial Pons.

Gómez Frechina, José (2019): "Pedro Orrente and the Nine Worthies”. En: Colnaghi studies journal, 4, Londres, pp. 114-135.

González Polvillo, Antonio (2009): "La Congregación de la Granada, el Inmaculismo sevillano y los retratos realizados por Francisco Pacheco de tres de sus principales protagonistas: Miguel Cid, Bernardo de Toro y Mateo Vázquez de Leca". En: Atrio, 15, Sevilla, pp. 47-72.

Gutiérrez, Constancio (1955): "España por el dogma de la Inmaculada: la embajada a Roma de 1659 y la bula 'Sollicitudo’ de Alejandro VII”. En: Miscelánea Comillas, 24, Madrid, pp. 7-480.

87 Valdivieso, 1999: 80. Sobre Miguel Cid, véase Vranich, 1973: 185-207.

88 Serrano Ortega, 1914: 220-227. Bassegoda i Hugas, 2016: 37-47, subraya la debilidad de las pruebas existentes acerca de la identidad del retratado en este cuadro de Pacheco, así como en el tradicionalmente identificado como Bernardo de Toro.

89 Bassegoda i Hugas, 1988: 151-176.

90 SOLVE IUBENTE DEO TERRARUM PETRE CATENAS y SANCTE PAULE APOSTOLE TU ES VAS ELECTIONIS. 
Harris, A. Katie (2007): From Muslim to Christian Granada: Inventing a City's Past in Early Modern Spain. Baltimore, Maryland: The Johns Hopkins University Press.

Hazañas y La Rúa, Joaquín (1918): Vázquez de Leca, 1573-1649. Sevilla: Sobrinos de Izquierdo.

Jesús María, fray Pedro de (1663): Vida, virtudes y dones soberanos del venerable y apostólico padre Hernando de Mata, con elogios de sus principales discípulos. Por Fr. Pedro de Jesús María, Monge de la Congregación Reformada, del Orden de san Basilio Magno, del Yermo del Tardón. Dedícalo al Misterio de la Inmaculada Concepción de María Santísima Señora Nuestra. Málaga: Mateo López Hidalgo.

Kendrick Downing, Thomas (1960): St. James in Spain. Londres: Methuen.

Lavenia, Vincenzo (2010): "La scienza dell'Immacolata. Invenzione teologica, politica, e censura romana nella vicenda di J. B. Poza". En: Roma moderna e contemporanea, 18, 1-2, Roma, pp. 179-211.

Lleó Cañal, Vicente (2015): "La Congregación de la Granada y los artistas sevillanos del Barroco”. En: Mata Induráin, Carlos/Morózova, Anna (eds.): Temas y formas hispánicas: arte, cultura y sociedad. Pamplona: Universidad de Navarra, pp. 201-217.

López García, María Trinidad (2005): "El auge del dogma de la Inmaculada Concepción auspiciado por el franciscano fray Antonio de Trejo, obispo de Cartagena, y la implicación del concejo de Murcia, a principios del siglo XVII". En: Campos y Fernández de Sevilla, Francisco Javier (coord.): La Inmaculada Concepción en España religiosidad, historia y arte, vol.1. El Escorial: Ediciones Escurialenses, pp.119-138.

Mergelina y Montejo, Alonso de (1628): Discurso Jurídico por la Inmaculada Concepción de María. Murcia: Luis Verós.

Meseguer, Juan (1955): "La Real Junta de la Inmaculada Concepción (1616-1817/20)". En: Archivo Íbero-Americano, 15, 59, Madrid, pp. 621-866.

Meyer, Paul (1883): “Les Neuf Preux”. En: Bulletin de la Société des Anciens Textes Français, 9, París, pp. 45-54.

Molinero, Marcelino (1955): "Fr. Antonio de Trejo y el Movimiento Inmaculista en la Diócesis de Cartagena". En: Archivo Ibero-Americano, 15, 59, Madrid, pp.1057-1071.

Moreno Martínez, Doris/Peña Díaz, Manuel (2011): “El jesuita Juan Bautista Poza y la censura”. En: Prosperi, Adriano (ed.): Riti di passaggio, storie di giustizia, vol. 3. Pisa: Scuola Normale Superiore di Pisa, pp. 159-170.

Nadal Iniesta, Javier (2009): "Fray Antonio de Trejo, el primer príncipe contrarreformista de la diócesis de Cartagena". En: Congreso Internacional Imagen Apariencia, Murcia: Universidad, pp. 1-14.

Nadal Iniesta, Javier (2015): "La repercusión del Concilio de Trento en la Capilla Mayor de la Catedral de Murcia durante el siglo XVII”. En: Griñán Montealegre, María, y García Pérez, Noelia (eds.): Perspectivas sobre la Historia del Arte, Murcia: Mestizo, pp.197-211.

Nadal Iniesta, Javier (2018): Arquitectura y manifestaciones artísticas en la Murcia del Seiscientos. Murcia: Universidad.

Pacheco, Francisco (1990): Arte de la pintura, edición a cargo de Bassegoda i Hugas, Bonaventura. Madrid: Cátedra.

Pascual Martínez, Lope (1974): "La embajada a Roma de Fray Antonio de Trejo, obispo de Cartagena". En: Anales de la Universidad de Murcia, Filosofia y Letras, 32, Murcia, pp. 21-42.

Pou y Martí, José María (1931): Embajadas de Felipe III a Roma pidiendo la definición de la Inmaculada Concepción de María. Vich: Seráfica.

Rivas Carmona, Jesús (1994): Los trascoros de las catedrales españolas: estudio de una tipología arquitectónica. Murcia: Universidad.

Rivas Carmona, Jesús (2001): “El trascoro de muro a capilla”. En: Yzquierdo Perrín, Ramón (ed.): Los coros de catedrales y monasterios: arte y liturgia, A Coruña: Fundación Pedro Barrié de la Maza, pp. 187-204.

Rivas Carmona, Jesús (2003): "Contrarreforma, obispos franciscanos y catedrales: el ejemplo del sur de España". En: Peláez del Rosal, Manuel (ed.): El franciscanismo en Andalucia, Priego de Córdoba: Cajasur, pp. 153-176.

Ruiz Hernando, José Antonio (1966): "La capilla de la Concepción de la Catedral”. En: Estudios segovianos, 94, Segovia, pp. 650-671.

Ruiz-Gálvez Priego, Estrella (2006): "La Inmaculada, emblema de la firmeza femenina". En ARENAL, 13, 2, Granada, pp. 291-310.

Sánchez-Rojas Fenoll, María del Carmen (1981): "Escultura del siglo XVII en Murcia”. En: Anales de la Universidad de Murcia. Filosofia y Letras, 38, 3, Murcia, pp. 221-255.

Sánchez Rojas-Fenoll, María del Carmen (1987): "La capilla del trascoro de la Catedral de Murcia”. En: AA. VV.: Homenaje al profesor Juan Torres Fontes, vol. 2. Murcia: Universidad, pp. 1535-1545.

Sánchez-Rojas Fenoll, María del Carmen (2010): “Antonio de Trejo, obispo de Murcia. Ejemplo de personalidad contrarreformista”. En: Ramallo Asensio, Germán Antonio (ed.): La catedral guía mental y espiritual de la Europa Barroca Católica, Murcia: Universidad, pp. 549-568.

Schroeder, Horst (1971): Der Topos der Nine Worthies in Literatur und bildender Kunst. Göttingen: Vandenhoeck and Ruprecht.

Sedlacek, Ingrid (1997): Die Neuf Preuses: Heldinnen des Spätmittelalters. Marburg: Jonas-Verl.

Segado Bravo, Pedro (1955): "El arquitecto carmelita fray Alberto de la Madre de Dios, tracista del santuario de la Vera Cruz de Caravaca (Murcia)”. En: AA. VV.: Homenaje al profesor Martín González. Valladolid: Universidad, pp. 261-268.

Serrano Ortega, Manuel (1914): "Dos joyas concepcionistas desconocidas de la pictórica sevillana". En: Boletín de la Real Academia de la Historia, 64, Madrid, pp. 220-227.

Stratton, Susan (1989): La Inmaculada Concepción en el arte español. Madrid: Fundación Universitaria Española.

Tomassetti, Luigi (1867): Bullarium Romanum, XII. Turín: Seb. Franco, H. Fory et Henrico Dalmazzo editoribus, poi A. Vecco et sociis. 
Valdivieso, Enrique (1999): “Inmaculada Concepción con Miguel del Cid”. En: Morales, Alfredo J. (ed.): Velázquez y Sevilla (Catálogo de la Exposición), vol. 1. Sevilla: Junta de Andalucía, p. 80.

Villalmonte, Alejandro de (1990): "Duns Escoto, la Inmaculada y el pecado original”. En: Collectanea franciscana, 60, Roma, pp. 137-153.

Vranich, Stanko (1973): "Miguel Cid (c. 1550-1615); un bosquejo biográfico". En: Archivo Hispalense, 56, Sevilla, pp. 185-207.

Wadding, Luke (1624): Legatio Philippi III et IV Catholicorum Regum Hispaniarum ad SS. DD. NN. Paulum PP. V. et Gregorium XV. De definienda Controuersiâ Immaculatae Conceptionis B. Virginis Mariae (per D. Fr. Antonium a Trejo). Lovaina: ex officina Henrici Hastenii.

Fecha de recepción: 17-III-2020

Fecha de aceptación: 21-VII-2020 